\title{
Imaginário serial: compartilhamento de arquétipos $^{1}$
}

\section{Serial imaginary: sharing archetypes}

\author{
Danielle Perin Rocha Pitta²
} Grenoble; e título do livro organizado por Jonathan Fruoco, Martin Andréa Rando e Arnaud Laimé: Imaginaire sériel. Les mécanismes sériels à l'œuvre dans l'acte créatif. 


\section{Resumo}

$\mathrm{Na}$ base de todo relato imagético estão os arquétipos, simultaneamente universais e específicos. Estes se expressam através do nível simbólico das imagens, culturalmente contextualizadas. Através da obra de Gilbert Durand, pode-se observar a lógica simbólica em ação tanto nos filmes como em seriados. Séries e novelas, percebe-se, devem o seu sucesso à força da redundância das imagens, à familiaridade, à sensação de segurança (imaginário transcendental), à distração do próprio cotidiano.

\section{Palavras-chave}

Imaginário serial, simbolismo, cinema, arquétipo.

\section{Abstract}

At the basis of all imaginary narrative there are the archetypes, both universal and specific. These are expressed through the symbolic level of images, culturally contextualized. Through Gilbert Durand's work, one can observe the symbolic logic in action in both films and serials. Series and novellas, it should be noted, owe their success to the redundancy of images, familiarity, sense of security (transcendental imaginary), and distraction of everyday life itself.

\section{Keywords}

Serial imaginary, symbolism, cinema, archetype. 
Já se perguntava Edgar Morin:

Em que sentido e de que maneira o universo cinematográfico moderno ressuscita o universo arcaico dos duplos? Por que o cinematógrafo, originalmente uma técnica de reprodução do movimento cujo uso parecia dever ser prático ou científico, tem desde o seu nascimento derivado em cinema, isto é em espetáculo imaginário? (MORIN, 1956 tradução minha).

Ora, para se falar em imaginário é necessário situar as bases epistemológicas utilizadas. Pode-se partir, para tanto, da colocação de Bachelard, segundo a qual "o simbolismo aberto nos prova que o homem tem necessidade de imaginar, que tem direito de imaginar, que tem o dever de aumentar o real" (BACHELARD, 1962, p. 5-6). Baseado nessa proposta e na obra do filósofo, o antropólogo Gilbert Durand, a partir do estudo das imagens contidas nas mais diversas expressões de diferentes culturas, vai estabelecer as estruturas antropológicas do imaginário, mostrando o quanto as imagens são primeiras, anteriores a formulações lineares e racionais. Se o cristianismo, entre outros, organiza o espaço considerando que o bem está localizado acima e o mal abaixo, não o faz certamente a partir de um raciocínio. J.-J. Wunenburger, em um estudo sobre Bachelard, coloca que este "adquiriu muito cedo a convicção de que as imagens formam a instância imediata e universal do psiquismo; o conceito sendo sempre segundo, pois construído a partir de uma oposição às imagens" (WUNENBURGER apud PITTA, 2005, p. 44).

\section{Em sequência da fenomenologia poética}

Para Gilbert Durand, "o Imaginário [...] isto é, o conjunto de imagens e de relações de imagens que constitui o capital pensado do 'homo sapiens' - nos aparece como o grande denominador fundamental onde veem se arrumar (se ranger) todos os procedimentos do espirito humano" (DURAND apud PITTA, 2005, p. 15). Ou ainda,

entende-se por "imaginário", tanto o museu de todas as imagens passadas ou possíveis quanto os procedimentos, mentais como materiais, de produzir imagens [...]. O imaginário [...] é a norma fundamental [...] perto da qual a contínua flutuação do progresso científico aparece como um fenômeno anódino e sem significado. [...] 
Entre a assimilação pura do reflexo e a adaptação limite da consciência à objetividade, constatamos que o imaginário constituía a essência do espírito, isto é o esforço do ser para erguer uma esperança viva diante e contra o mundo objetivo da morte. Para poder falar com competência do Imaginário não se deve confiar nas exiguidades e nos caprichos da sua própria imaginação, mas possuir um repertório quase exaustivo do Imaginário normal e patológico em todas as camadas culturais que nos propõem a história, as mitologias, a etnologia, a linguística e as literaturas. (DURAND apud PITTA, 2005, p. 15).

Difícil então falar em origem do imaginário compartilhado por filmes e séries para cinema e televisão. Consideramos aqui que o imaginário é o conjunto de imagens compartilhadas por um grupo social, logo filmes e séries fazem parte e simultaneamente ativam e recriam essas imagens. Trata-se de um diálogo.

Só posso aqui reproduzir o que já foi escrito tantas vezes sobre o vocabulário específico à teoria do imaginário e sobre suas estruturas. Será dada ênfase à noção de arquétipo por serem as matrizes das imagens.

Os arquétipos, nessa perspectiva teórica, são as imagens primeiras (fundamentais) de caráter coletivo e inato; o estado preliminar, a zona matricial da ideia. (JUNG, 2003). Constituem o ponto de junção entre o imaginário e os processos racionais. Exemplos: imagens universais do chefe, do alto; da mãe, do colo, do alimento.

No entanto, Durand diverge de Jung em alguns pontos. Diz ele:

Minha teoria das estruturas do imaginário é esta: contrariamente à Jung, que faz entrar no símbolo arquetipal muitas imagens que já são projeções, para mim o arquétipo é verbal, isto é, no final das contas, ligado à nossa gestualidade de base, que remonta à verticalidade da nossa avó Lucy, à frontalidade da sua visão, à evolução da sua mão etc., ou seja, à uma porção de movimentos que nos dota de uma verbalidade: o verbo é um som acompanhando a ação - Bachelard bem havia dito: isto tudo está relacionado com a nossa hominização ${ }^{3}$ (DURAND, 2001, tradução minha).

No original: "Ma théorie des structures de l'imaginaire est celle-ci: contrairement à Jung, qui fait entrer dans le symbole archétypal beaucoup d'images qui sont déjà des projections, pour moi l'archétype est verbal, c'est-à-dire, en fin de compte, rattaché à notre gestuelle de base, qui remonte à la verticalité de notre grand-mère Lucy, à la frontalité de sa vision, à l'évolution de sa main, etc., bref à un tas de mouvements qui nous dotent d'une verbalité: le verbe est un son accompagnant I'action - Bachelard I'avait bien dit: tout cela est attaché à notre hominisation" (Le retour des dieux, un entretien par Patrice van Eersel - 2001). 
Cada arquétipo, entretanto, é representado em cada cultura de maneira específica através dos símbolos. O arquétipo é simultaneamente universal e específico na sua representação - a imagem arquetípica. Na minha compreensão, baseada nos pressupostos da antropologia do imaginário de Gilbert Durand, o arquétipo tem simultaneamente estas quatro dimensões: é estrutural, na medida em que se constitui como dinâmica profunda do imaginário (não se deve esquecer que todo "real" é antes imaginado), e é expressão dos gestos fundamentais (schemes) específicos do ser humano; é produção do sujeito, porque este é que dá vida ao arquétipo - no candomblé, por exemplo, diz-se "veja como a Oxum dele dança bem!"; e é uma revelação, pois que o arquétipo se traduz em símbolos que são, como diz Gilbert Durand, a epifania de um mistério. Ou ainda, como diz Regis Alain Barbier (2013): "um arquétipo é uma expressão radical de um estado-de-ser simbólico". Sabe-se, desde Cassirer, que o ser humano só apreende o universo através do símbolo. E o símbolo é todo signo concreto evocando algo ausente ou impossível de ser percebido. É uma representação que faz aparecer um sentido secreto. Os símbolos são visíveis nos rituais, nos mitos, na literatura, nas artes visuais e no cotidiano.

\footnotetext{
Entre a assimilação pura do reflexo e a adaptação limite da consciência à objetividade, constatamos que o imaginário constituía a essência do espírito, isto é, o esforço do ser para erguer uma esperança viva diante e contra o mundo objetivo da morte (DURAND, 1986, p. 296).
}

\section{Do arquétipo ao símbolo}

De que maneira arquétipos e símbolos se dão a ver no caso do cinema, dos seriados? É preciso levar em conta as bases da construção do imaginário, válidas tanto para as artes como para o cotidiano.

Morte e angústia existencial, por exemplo, expressam-se através das imagens relativas ao tempo. Ligados por uma lógica própria, os símbolos expressando a angústia se dividem em três grandes temas, sempre segundo G. Durand (1997): 
Símbolos teriomórficos (relativos à animalidade): são aqueles ligados à animalidade angustiante sob várias formas. É necessário distinguir o animal físico do animal simbólico. Assim são encontrados: o fervilhamento (grouillement), que diz respeito a larvas amontoadas visguentas e agitadas, a insetos em geral, e que expressam a repugnância primitiva diante da agitação incontrolável, que é o arquétipo do caos - a animação, o movimento em si, incontrolável, dos grandes animais. Aí se encontram principalmente o cavalo e o touro que, em diversas mitologias, representam a morte. "O folclore e as tradições populares germânicas e anglo-saxônicas conservaram este significado negativo e macabro do cavalo: sonhar com um cavalo é sinal de morte próxima" (DURAND, 1997, p. 73). O tropel do animal, relacionado ao trovão, já é mau agouro (os cineastas bem o sabem). 0 touro desempenha o mesmo papel imaginário do que o cavalo: "todas as culturas paleo-orientais simbolizam o poder meteorológico e destruidor pelo touro" (DURAND, 1997, p. 75). É a mesma angústia que motiva os dois simbolismos: a angústia diante da mudança, da fuga do tempo, do mau tempo. A mordicância, ou ato de morder, de devorar, é outro aspecto angustiante da animalidade. Aqui, a imagem significativa primeira da animalidade não está mais centrada no movimento, seja ele formigamento ou tropel, mas na boca aberta e cheia de dentes. Nessa ordem de pensamento vão ser encontrados os lobos (principalmente para o Ocidente), os leões (para os trópicos e o equador), as onças pintadas (para o Brasil), que em diversas mitologias e contos infantis devoram, sejam as pessoas, seja a lua (que representa o tempo), como também os ogros (comedores de criancinhas), e o próprio Kronos, o tempo, devorando seus filhos. "Terror diante da mudança e diante da morte devorante, tais parecem ser os dois primeiros temas negativos inspirados pelo simbolismo animal" (DURAND, 1997, p. 77).

Símbolos nictomórficos (relativos à noite): dizem respeito à escuridão. Eles se subdividem em: situação de trevas, seja provocada, como é o caso do choque negro do Rorschach (teste projetivo em psicologia), seja natural como a cegueira. No folclore, a hora final do dia, ou a meia-noite, são consideradas muito perigosas: é a hora em que os animais maléficos e os monstros infernais se apossam dos 
corpos e das almas (BACHELARD). Os psicólogos notam, por sua vez, que a mancha negra (RORSCHACH), induzindo a situação de trevas, provoca imagens de caos, de agitação desordenada. Já a cegueira encontra-se frequentemente, nas diversas mitologias, sob os traços do rei cego, símbolo do inconsciente, que aqui se torna decadência - mas deve-se levar em conta que o velho rei cego muitas vezes tem por parceiro o jovem herói (muitos folhetos de literatura de cordel retratam essa situação); da água escura, triste - aquela do rio que passa para nunca mais voltar; da água estagnada - convite ao suicídio, cujo fundo esconde entidades maléficas (como tão bem observou Bachelard) presentes em todos os folclores e mitologias (no Brasil, por exemplo, Iemanjá leva seus amantes para o fundo do mar); do espelho, réplica da água estagnada, convite a passar para o outro lado (como nos filmes de Cocteau em que o personagem mergulha no espelho e tem grande dificuldade em se locomover do outro lado); da cabeleira, que vai "insensivelmente inclinar os símbolos negativos [...] para uma feminização" (DURAND, 2012, p. 99) - pelo menos no Ocidente, onde é a mulher que tem, ou tinha, cabelos longos -, por suas ondulações, réplica da água corrente, que implica a feminização da água, mas aqui num feminino noturno de mulher fatal, que por sua vez estabelece a relação água/ lua (marés), lua (mês)/menstruação, lua (tempo)/morte, o que traz a imagem da mãe terrível, devoradora, e da vamp, remetendo a uma feminilidade animalizada que leva à aranha, à mulher aranha, que então leva ao liame (instrumento que liga: linhas, cordões etc.) que sufoca e enforca, e por aí vai.

Símbolos catamórficos (relativos à queda): são aqueles relativos à experiência dolorosa da infância. A queda tem a ver com o medo, a dor, a vertigem, o castigo (como no mito de Ícaro). Mas a queda frequentemente é uma queda moral (pelo menos no Ocidente) e tem então a ver com a carne, com o ventre digestivo e o ventre sexual, e daí com o intestino, o esgoto, o labirinto. Cai-se no abismo, e o abismo pode ser tentação.

Aí estão, pois, as imagens do tempo negativo, do tempo de morte, largamente utilizadas pelos cineastas, principalmente nos filmes de terror - imagens arquetipais universais. Em réplica a esses símbolos vêm aqueles 
relativos à resposta à angústia existencial: heroicos, místicos, cíclicos etc. (DURAND, 1997), que não caberiam neste artigo.

\section{Do símbolo ao mito}

Foi visto que "um isomorfismo contínuo religa uma série de imagens díspares à primeira vista, mas cuja constelação permite induzir um regime multiforme da angústia diante do tempo" (DURAND apud PITTA, 2005 p. 26). Diante desse tempo negativo, segundo Gilbert Durand, só existem três soluções possíveis para sobreviver: pegar as armas e destruir o monstro (a morte), criar um universo harmonioso no qual ela não possa entrar ou ter uma visão cíclica do tempo no qual toda morte é renascimento (DURAND apud PITTA, 2017). É fácil reconhecer esses tipos de dinamismo em ação em filmes ou séries.

Importante ainda destacar a importância do mito, relato que fundamenta toda cultura, inclusive a nossa, que serve de modelo para a construção da identidade, individual e coletiva, que tem uma dimensão pedagógica e que se encontra subjacente à toda obra de arte, inclusive em filmes e seriados.

\section{Imaginário e seriados}

O sucesso de filmes ou seriados depende, pois, da capacidade do diretor em utilizar arquétipos e dinâmicas míticas, tratadas em relação às especificidades do tempo e do espaço onde se atualizam, para fornecer elementos de compreensão e de ação positiva no cotidiano.

Uma grande categoria de filmes é aquela relacionada ao sonho: Harry Potter (Chris Columbus, 2001-2003; Alfonso Cuarón, 2004; Mike Newell, 2005; David Yates, 2007-2011), por exemplo, utiliza os arquétipos em um cenário de sonho, algo vivenciado pelo espectador como se estivesse fora da realidade, mas que permite, entretanto, à criança/adolescente exercitar seu poder sobre os outros e sobre o mundo. Dá as soluções simbólicas para que uma criança solitária e rejeitada (assim como se sentem grande parte delas) se torne livre e poderosa. 
Nesse sentido é que Gilbert Durand fala em fantástica transcendental: "nesta perspectiva durandiana, a pedagogia do imaginário tem na função de eufemização da imaginação a sua justificação, porquanto o sentido último da função fantástica reside no eufemismo. E aqui o eufemismo afirma não somente o poder do homem de melhorar o mundo, como também se ergue contra o destino mortal" (ARAÚJO; TEIXEIRA, 2009).

Já em Game of Thrones (David Benioff e D. B. Weiss, 2011-hoje), apesar do enquadramento como série inserida na categoria do fantástico, verifica-se o acento colocado em cenas de violência e sexo, que remetem ao grotesco tal como definido por Muniz Sodré e Raquel Paiva (2002), apresentando quatro modalidades expressivas, a saber:

Escatológico: trata-se das situações que fazem referência a dejetos, secreções, partes baixas do corpo, entre outros. Sodré e Paiva citam o exemplo de A Morte e A Morte de Quincas Berro D'água, o personagem mediano descreve a tia Marocas como um "saco de peidos".

Teratológico: são as referências risíveis a monstruosidades, aberrações, deformações, bestialismos etc. Um exemplo é o personagem principal da obra O Corcunda de Notre-Dame, de Victor Hugo, e Bocatorta, de Monteiro Lobato.

Chocante: está presente nas duas formas anteriores e tem o objetivo de provocar no espectador ou contemplador um choque perceptivo, geralmente com intenções sensacionalistas, podendo ser chamado também de grotesco chocante.

Crítico: ocorre quando o grotesco presente no objeto visado expõe um discernimento formativo, ou seja, além da percepção sensorial do fenômeno, é desvelado o que se tenta ocultar (convenções, ideias) expondo de modo risível os mecanismos do poder abusivo. Esse efeito pode tomar a forma da caricatura ou da paródia provocando inquietações nas situações estabelecidas (SODRÉ; PAIVA apud FERREIRA; OLIVEIRA, 2013).

Séries e novelas, pode-se observar, devem o seu sucesso à força da redundância das imagens, à familiaridade, à segurança (imaginário transcendental), à distração do próprio cotidiano. Como destaca Wunenburger (2000, p. 13, tradução minha): "a televisão se torna [...] o relógio, o barómetro, o giroscópio da vida familiar, profissional e social". 
Sodré e Paiva antecipam que o ethos dos programas televisivos corresponde a uma espécie de "comunicação do grotesco" em que o estranho e o repulsivo não têm outra finalidade senão gerar o choque perceptivo, que capta a atenção do espectador e o encaminha para um clímax sensacionalista. No texto, o teratológico e o escatológico apenas referendam o clima gótico-fantástico da narrativa, alheios a qualquer entrelinha crítica (FERREIRA; OLIVEIRA, 2013).

A redundância permite dar ênfase às imagens diretoras de uma obra e assim orientar o espectador para sua dimensão mítica subjacente. Procurar essas redundâncias é o que fazem os estudiosos à procura dos seus significados profundos ${ }^{4}$. Essa redundância tranquiliza o espectador pela segurança do seu retorno, pela compreensão do já conhecido e, logo, dispensa maiores esforços. As imagens se tornam familiares e então não apresentam perigo.

Os organizadores do colóquio Imaginaire sériel: colloque international5 , em Grenoble, partiram dos resultados de dois anos de seminários sobre o tema "Mitos e séries de TV: olhares cruzados" ${ }^{\prime \prime}$, realizados em 2013 e 2014, na Universidade Stendhal, e destacam que "Mircea Eliade vê na reprodução dos arquétipos a razão de todo gesto humano, Claude Lévi-Strauss sublinha a importância da recursividade dos mitemas, enquanto Gilbert Durand defende o princípio de redundância aperfeiçoante"7.

Um livro acaba de ser publicado a esse respeito (não tive ainda acesso a ele). Trata-se de Imaginaire sériel: les mécanismes sériels à l'œuvre dans l'acte créatif, organizado por Jonathan Fruoco, Andréa Rando Martin e Arnaud Laimé, que interroga sobre o sucesso das séries de televisão, ou novelas, e questiona sobre por que o impacto de uma obra sobre a nossa imaginação é mais importante e fecundo quando ela é concebida para ser veiculada por séries.

Trata-se dos métodos criados por Gilbert Durand: mitocrítica e mitanálise. Cf. MUGA, H. A. O imaginário na obra cinematográfica de João César Monteiro. Tese apresentada à Universidade Fernando Pessoa - Doutorado em Ciências Sociais, 2015. 
Este livro foi concebido, em primeiro lugar, para examinar o impacto da serialidade sobre o nosso imaginário e, em segundo lugar, para compreender melhor o imaginário da serialidade. Além dos debates ideológicos e metodológicos nos estudos da imaginação, um ponto parece unânime: o imaginário operaria principalmente através dos mecanismos de repetição. Forjando a noção de imaginário serial, o livro se propõe a reenviar à estrita solidariedade entre, por um lado, esta faculdade que determina e organiza estes vaivéns ricos de significado entre a experiência e a sua representação e, por outro lado, um procedimento baseado na repetição cadenciada de um ou vários paradigmas, em um conjunto isolável determinado e coerente, o que permite sua reprodução e inflexão. Nesta perspectiva, as obras de arte de seriais formam naturalmente um campo de pesquisa privilegiado, já que fazem da recursividade e da redundância um princípio de construção. Toda disciplina artística é suscetível de lançar luz sobre as questões levantadas. Assim, os autores propõem-se a analisar tanto a literatura de série, tais como romances serializados ou ciclos de literatura infanto/juvenil ou ficção científica, como as séries de TV, a música serial, e ainda as séries de histórias em quadrinhos, o cinema ou as artes. ${ }^{8}$

Enquanto um texto cientifico vai ter como meta a explicação, as imagens veiculadas pela tecnologia, através de sua dimensão simbólica, vão ter como meta provocar a empatia, a compreensão através do compartilhamento das emoções que ocorre a nível arquetípico. Através da vivência da alteridade, por identificação com o protagonista, são veiculados sentimentos de conforto e segurança, pois se tem a certeza de que este, o protagonista, na maioria dos casos, não morrerá. Não se deve esquecer que é o simbolismo que liga o homem à sociedade e é o saber que constitui a imagem, saber que pressupõe não a procura de uma verdade precisa, mas o clareamento de uma "realidade velada".

Dentro de um cotidiano frequentemente violento e opressor, partilhar da vida do outro, com a segurança de que ele estará de volta (no dia seguinte, ou no próximo episodio), sobreviverá aos desafios, e se encaminhará para um "final feliz", traz um pouco de reconforto. 


\title{
À guisa de conclusão
}

Finalmente, não posso deixar de citar, como conclusão, este trecho longo, mas a meu ver indispensável:

\begin{abstract}
Hoje já não são mais os grandes sistemas religiosos que conservam os regimes simbólicos e as correntes míticas, mas antes as belas artes, para as elites, e a imprensa, a publicidade, as novelas ilustradas, a fotografia, a televisão, o cinema (sob vários formatos) para o público em geral, tendo, ultimamente, Gilbert Durand acrescentado o efeito perverso e a explosão do vídeo. Assim, o inalienável repertório de toda a fantástica (Durand), com os seus poderes da imagem (René Huyghe), vê-se abafado por uma civilização da imagem, mesmo até por uma sobre-excitação e inflação de todo tipo de imagens, que, ao contrário daquilo que se possa pensar, em nada contribuem para criar o que Gaston Bachelard denominou de "poética do devaneio" (ARAújO; TEIXEIRA, 2009).
\end{abstract}

\section{Referências}

ARAÚJO, A. F.; TEIXEIRA M. C. S. Gilbert Durand e a pedagogia do imaginário. Letras de Hoje, Porto Alegre, v. 44, n. 4, p. 7-13, out./dez. 2009.

BACHELARD, G. Message de Gaston Bachelard. Société de Symbolisme (Genève), Cahiers Internationaux du Symbolisme, n. 1, 1962, p. 5-6.

BARBIER, R. A. Natureza e importância dos arquétipos para o panteísmo. Instituto Universo Panteísta, [S.I.], set. 2013. Disponível em: <https://goo.gl/C1ubd8>. Acesso em: 6 out. 2017.

DURAND, G. Mito e sociedade: a mitanálise e a sociologia das profundezas. Lisboa: Regra do Jogo, 1983.

A Imaginação Simbólica. São Paulo: Cultrix, 1988. 
As estruturas antropológicas do imaginário. São Paulo: $1^{a}$ edição: Martins Fontes, 1997. 4ª edição: Martins Fontes, 2012

. Campos do imaginário. Lisboa: Instituto Piaget, 1998.

. O imaginário: ensaio acerca das ciências e da filosofia da imagem. Rio de Janeiro: Difel, 1999.

. Le retour des dieux. Propos recueillis par Patrice Van Eersel. Nouvelle clés, [S.I.], 2001.

- Ciência do homem e tradição: o novo espírito antropológico. São Paulo: Triom, 2008.

FERREIRA, F.; OLIVEIRA, M. Resumo do livro "O Império do Grotesco". O mundo do grotesco. 2013. Disponível em: <http://bit.ly/2kFFdoW>. Acesso em: 11 out. 2017.

FREITAS, C. F. Un cinéma possible: une analyse socio-anthropologique de la production cinématographique brésilienne dans la postmodernité. Tese (Doutorado em Sociologia) - Université Paris Descartes, Paris, 2001.

FRUOCO, J.; LAIMÉ, A.; MARTIN, A. R. (Orgs.). Imaginaire sériel: les mécanismes sériels à I'œuvre dans I'acte créatif. Grenoble: UGA Éditions, 2017.

JUNG, Carl Gustav. Os arquétipos e o inconsciente coletivo. Petrópolis: Vozes, 2003.

MARCHAND, F. Avant-propos: le cinéma ou les territoires de l'imaginaire. Entrelacs, Toulouse, p. 1-4, ago. 2011. Disponível em: <https://goo.gl/V4SzXn>. Acesso em: 24 maio 2017. 
MORIN, E. Le cinéma ou I'homme imaginaire. Paris: Les Éditions de Minuit, 1956.

PITTA, D. P. R. Iniciação à teoria do imaginário de Gilbert Durand. $1^{\text {a }}$ ed. São Paulo: Atlântica Editora, 2005; 2. ed. Curitiba: Editora CRV, 2017.

SODRÉ, M.; PAIVA, R. O império do grotesco. Rio de Janeiro: Mauad, 2002.

WUNENBURGER, J.-J. L'homme à l'âge de la télévision. Paris: Presses Universitaires de France, 2000.

ZUMTHOR, P. Permanência da voz. In: FUNDAÇÃO PARA O DESENVOLVIMENTO DA EDUCAÇÃO. Lições de Cinema, 5: cinema e televisão - histórias com imagens e som na moderna sociedade oral. 2. ed. São Paulo: FDE, 1993. p. 48-58.

submetido em: 11 jul. 2017 | aprovado em: 16 ago. 2017 